\title{
Nest composition and yolk hormones: do female European starlings adjust yolk androgens to nest quality?
}

\author{
Helga Gwinner ${ }^{a^{*}}$, Elisabeth Yohannes ${ }^{\mathrm{a}, \mathrm{b}}$ and Hubert Schwabl ${ }^{\mathrm{c}}$ \\ aMax Planck Institute for Ornithology, Behavioural Ecology \& Evolutionary Genetics PO Box 1564, \\ D-82305 Starnberg (Seewiesen), Germany \\ ${ }^{b}$ University of Constance, Limnological Institute, Stable Isotope Lab, Mainau Str. 252 D-78464, \\ Germany \\ 'Washington State University, Center for Reproductive Biology, School of Biological Sciences, \\ Pullman, WA 99164-4236, USA \\ *E-mail: hgwinner@orn.mpg.de
}

\begin{abstract}
The nest is a key element of avian reproductive fitness. It provides the developmental environment for the embryo and nestling thereby affecting their quality and survival. Nests are often constructed by the male and nest quality, elaboration, and ornamentation vary among males in a species. Therefore, male nest-building behaviour is likely under sexual selection and females may use male nest-building behaviour and nest features as cues in mate choice and their own reproductive investment. We tested this hypothesis in European starlings (Sturnus vulgaris). Male starlings present green plants to females during their courtship display and furbish their nests with variable quantities of fresh green plants. The highest frequency of plant incorporation into the nest occurs during pair formation and oogenesis. We determined nest composition and measured yolk testosterone concentrations in eggs. Yolk testosterone concentrations were positively correlated with the amount of green plant material in nests. Because males use green nest material in courtship and green nest material positively affects nestlings' development, we suggest that female European starlings use male nest-building effort, ritualised courtship display of green plants, and nest characteristics in mate choice, and adjust yolk testosterone levels in the eggs to the quality of the nest to optimise offspring growth.
\end{abstract}

Keywords: green nest materials, mate choice, yolk androgens, European starling (Sturnus vulgaris)

\section{INTRODUCTION}

The nest, providing the developmental environment of avian embryos and nestlings, affects offspring quality and survival (e.g., Alvarez et al., 2013, Hansell and Overhill, 2000, Deeming, 2002). Therefore, nest construction is expected to be under natural selection. In many bird species, males construct the nest and nest quality, composition, and ornamentation vary among males. Male bowerbirds (Ptilonorhynchidae) use nest ornamentation and male black wheatears (Oenanthe leucura) use stone piling at the nest to attract females while males of other species display ornaments that they incorporate into the nest to the female as an integral element of ritualised courtship (Moreno et al., 1994, Hansell and Overhill, 2000; Moreno, 2013). Hence, male nest building behaviour and/or resulting nest quality and features are predicted to be shaped by sexual selection.

European starlings (Sturnus vulgaris) build their nests in natural cavities or nest boxes. They often breed in colonies where males occupy one or more nest holes. Mainly males build the nest. They use dry materials such as twigs, old leaves, or grass but they also incorporate fresh green plants, preferably those with volatile compounds (Clark and Mason, 1985; Clark, 1991; Gwinner, 1997). Males display these fresh green plants (herbs) in an eyecatching manner to prospecting females during nest site advertisements (Kessel, 1957; Feare, 1984; Eens et al., 1993; Gwinner, 1997). The incorporation of fresh herbs into nests peaks about 5 days before the first egg is laid, at the time when the pair forms and the eggs of the clutch begin to be yolked, and ceases with the end of the courtship phase. This timing suggests a role of this behaviour in mate attraction (Gwinner, 1997; Brouwer and Komdeur, 2004; Veiga et al., 2006;).

Experimental studies have shown that female starlings are attracted to males carrying plants and/or possessing nests containing fresh herbs. For example, in a Dutch starling colony females laid clutches into $100 \%$ of experimental nests containing green material but only $40 \%$ of nests where greenery had been removed (Brouwer and Komdeur, 2004). In an aviary experiment, $100 \%$ of females produced a clutch when greenery was available; while only $33 \%$ of females laid eggs when no green 
nest material was offered. In a behavioural experiment, females were more interested in a male mount that displayed a piece of herb in the bill than in a dummy without herb (Gwinner, 2013). Females also tended to visit nests with greenery more often than nests without greenery (Lampert, 1997). Finally, polygynous male spotless starlings (Sturnus unicolour) incorporated more greenery into nests than monogynous males (Veiga et al., 2006 ,). Therefore, the display of green-plants by the male during courtship and the presence of green plants in the nest appear to be attractive to female starlings (see Dubiec et al., 2013 for a review).

Green nest materials benefit nestlings and the female. Nest greenery enhanced nestling growth, inhibited bacterial and mite growth, and positively influenced nestlings' blood parameters (Clark and Mason, 1985; 1988; Clark, 1991; Gwinner et al., 2000; Gwinner and Berger, 2005). Moreover, nest greenery benefitted female egg incubation effort (Gwinner, 2013). Thus, female starlings are predicted to use nest composition or the males `ritualised display of plants to assess the prospects of raising healthy young in their nests.

Theory predicts that females respond to cues of male reproductive skills and investment by adjusting their own reproductive investment, such as clutch size, egg quality, and egg composition (e.g., Cunningham and Russell, 2000). One of these responses is the concentration of yolk hormones such as testosterone that enhances nestling growth in some species, including the European starling (e.g., Schwabl, 1996; Eising et al., 2001; Tschirren et al., 2005; Pilz et al., 2004). Previous researches in various species have demonstrated that yolk androgen concentrations vary with male plumage colour (Navarra et al., 2006; Kingma et al., 2009), tail length (Gil et al., 2006; but see Saino et al., 2006), and song complexity (Gil et al., 2004; Tanvez et al., 2004; but see Marshall et al., 2005). We hypothesised that female starlings adjust yolk androgen concentrations to male-designed nest quality (i.e., herb content) and investigated this hypothesis in a free-living starling population.

\section{METHODS}

\section{Egg collection and hormone extraction}

In a starling nest-box colony near Andechs, Southern Germany $\left(47^{\circ} 58^{`} \mathrm{~N}, 11^{\circ} 11^{`} \mathrm{E}\right), 54$ nest boxes were fixed about $6 \mathrm{~m}$ apart on trees in a height of approximately $4 \mathrm{~m}$ at the edges of meadows and woodland. In the first year (1997) we collected green nest material and the first and fifth egg from 26 and 19 boxes, respectively. In the second year (2004) we collected the first and fifth egg from 15 and 24 boxes, respectively. In two study years, in April and May, we determined egg sequence by marking eggs during daily nest checks and collected the first egg (1 day after laying) and the fifth egg. We weighed the yolks to the nearest $0.01 \mathrm{~g}$ and stored them at $-80^{\circ} \mathrm{C}$ until they were transported on dry ice to Pullman, Washington State, USA for hormone analyses.

The procedures for extraction and radio-immunoassays of the steroid hormones (androstenedione, 5alphadihydrotestosterone, and testosterone,) followed the procedures described previously (Schwabl, 1993). Recoveries for androstenedione, 5alphadihydrotestosterone, and testosterone were 67, 33, and $54 \%$, respectively. Intra-assay variation was 7, 9, and $5 \%$, respectively. All samples were run in a single assay. 5-alpha-dihydrotestosterone was only measured in a subset of samples. Here we only report data on testosterone because the other two androgens were unrelated to green nest material.

\section{Nest sampling}

In the first study year (1997), we collected nest herbs (but not other construction material) every day around noon, so females could investigate the males' nest building performance undisturbed during the morning hours. We dried and weighed the herbs. The amount of green nest materials was defined as the sum of greenery incorporated into the nest during the courtship period. In the second study year (2004, in the context of another study) we collected nests when nestlings were 14 days old and replaced them with nests of about $100 \mathrm{~g}$ dry grasses (equivalent to the mean mass of a starling nest). The natural nests were dried for one month at room temperature and components classified into the following nest construction material: "dry nest material": dry twigs and dry grasses; and initially "green nest material": herbs which were determined by their greenish colour.

\section{Statistical analysis}

We log-transformed yolk testosterone and mass of green nest material to obtain normal distributions. We analysed effects of study year, laying sequence (first and fifth egg), green nest material and date (corrected for the onset of laying in the population in each year) on yolk testosterone using univariate GLM (SPSS 18 PASW). We tested all possible interactions, removed variables which were insignificant. The model was significant only for yolk testosterone but not for yolk androstenedione and 5-alpha-dihydrotestosterone; therefore we only present results for yolk testosterone. Results for yolk testosterone concentrations and content were qualitatively similar; therefore we only report yolk testosterone concentrations (pg mg-1 yolk). The differences between the two study years were tested with an independent sample $t$-test and the relationships between mass of dry and green nest material, date and yolk testosterone with Spearman's rho correlation. 


\section{RESULTS}

\section{Nest composition}

Mass of dry and green nest materials were negatively related to each other (Spearman's rho $=0.46, P=0.03$, $n=21$ ). The mass of green nest material increased with laying date (Spearman's rho $=0.52, P=0.01, n=26$ ), while the mass of dry nest-material decreased (Spearman's rho $=-0.54, P=0.01, n=21$, Figure 1). Yolk testosterone concentration in the first and fifth egg was unrelated to mass of dry nest material (Spearman's rho $=-0.32, P=$ $0.16, n=21$; year 2 only) but was positively correlated with green material (Spearman's rho $=0.4, P=0.01, n$ = 41; data from years 1 and 2 combined).

\section{Green nest material and yolk testosterone}

When we used data over the entire breeding season (first and second brood) in the model we found very strong effects of green nest material $\left(F_{1,84}=13.9, P<0.0001\right)$ and year $\left(F_{1,84}=19.3, P<0.0001\right)$ and less strong but significant effects of laying sequence $\left(F_{1,84}=4.4\right.$, $P=0.038)$ and date $\left(\mathrm{F}_{1,84}=4.9, P=0.029\right)$ on yolk testosterone. Date and green nest material were strongly correlated (Spearman: $r=0.57, P<0.0001, n=85$ ), possibly resulting from polygynous males increasing the amount of incorporated greenery in their secondary nests later in the season (Gwinner, 1997). When we controlled for date by restricting the analysis to first nests initiated between April 12 to 22 there was no correlation between date and greenery (Spearman's rho: $P=0.99, r=0.001$; $n=54$ ).

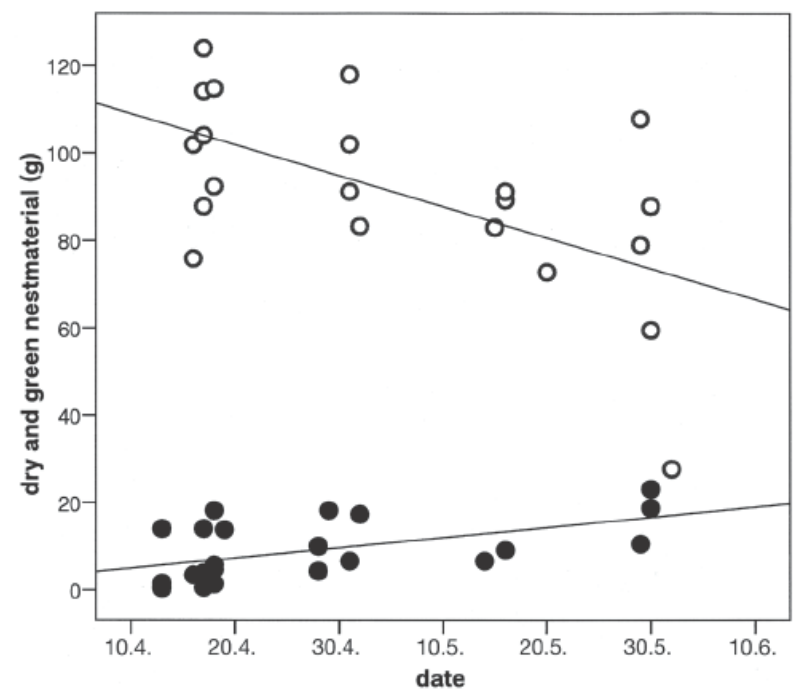

Figure 1 Mass of dry (open circles) and green (closed circles) nest material in nests constructed from 10 April to 10 June.
The final analysis revealed strong effects of year $\left(F_{1,54}\right.$ $=17.45, P<0.0001)$ and green nest material $\left(\mathrm{F}_{1^{\prime} 54}=\right.$ $8.64, P=0.005)$, but not of laying sequence $\left(\mathrm{F}_{1,54}=3.04\right.$, $P=0.09)$ and date $\left(\mathrm{F}_{1,54}=0.25, P=0.63\right)$ on yolk testosterone concentrations (Figure 2).

The study year had a strong effect on testosterone and amount of greenery.

In the first year, yolk testosterone levels were higher than in the second year. Conversely, in the second year more greenery was incorporated into nests (Table 1).

\section{DISCUSSION}

This study shows a strong positive correlation of yolk testosterone concentrations with the amount of green herbs incorporated by male starlings into their nests. This relationship was significant despite differences in yolk testosterone concentrations and mass of green nest material between study years. The result is consistent with the hypothesis that female starlings adjust egg quality, in this case yolk testosterone concentrations, to the amount

Table 1 Yolk testosterone concentrations (pg mg ${ }^{-1}$ yolk) and amount of green herbs (g) incorporated by male starlings into their nests. The concentration of yolk testosterone and greenery varied between the two study years (year 1 and 2)

\begin{tabular}{|c|c|c|c|}
\hline & Year 1 & Year 2 & $\mathrm{P}$ \\
\hline \multicolumn{4}{|c|}{ Yolk-testosterone (pg mg-1 yolk) } \\
\hline Egg 1 & $1.05 \pm 0.1$ & $0.69 \pm 0.1$ & $0.0001 *$ \\
\hline Egg 5 & $1.32 \pm 0.1$ & $0.86 \pm 0.1$ & $0.002 *$ \\
\hline Greenery (g) & $1.8 \pm 0.91$ & $7.1 \pm 2.3$ & $0.015^{*}$ \\
\hline
\end{tabular}

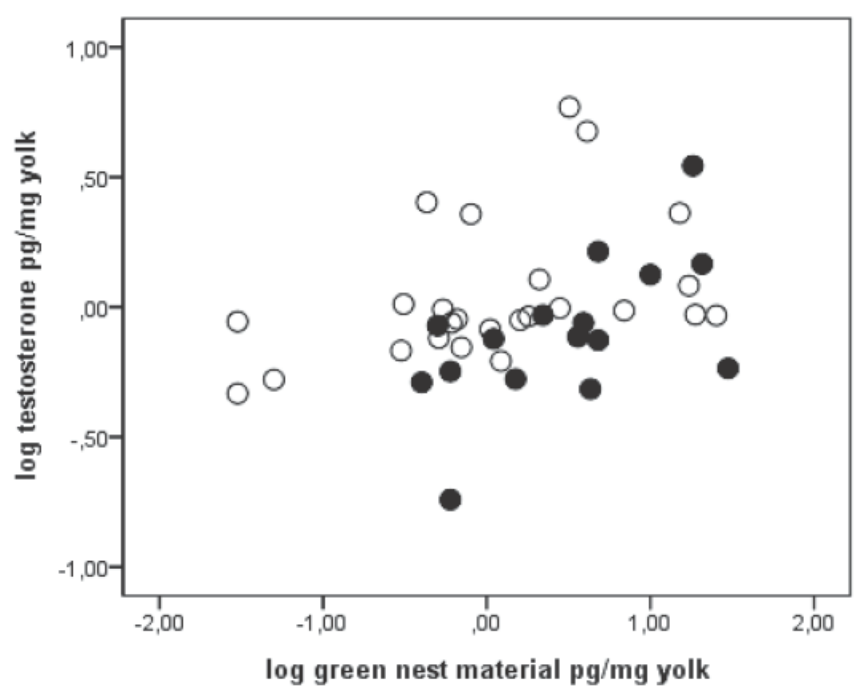

Figure 2 Relationship of yolk testosterone concentrations in the first egg and mass of green material in nests during the reproductive season of the two study years: year 1 open circles, year 2 closed circles. 
of herbs in their nests and/or to the male's behaviour of displaying nest herbs to the female during courtship.

The concentration of yolk testosterone varied between the two study years. Environmental conditions like food quality, predation risk, competition for nest boxes, prevalence of parasites, may have been responsible for these differences. All of these factors have been shown to influence yolk hormones. For example, high quality food increased yolk testosterone (Vergauwen et al., 2012); in Great tits (Parus major), experimentally increased predation risk resulted in lower yolk testosterone (Coslovsky et al., 2012), and yolk testosterone was lower when females were exposed to nidicolous hen fleas (Heylen et al., 2012) and in nests with high ectoparasite loads (Tschirren et al., 2004). A significant higher load of red fowl mites (Dermanyssus gallinae) in the second year of our study (data not shown) could have been a cause of the lower yolk testosterone levels in that year. The higher plant mass in nests of the second study year could have resulted from a higher frequency of polygynous males who add more greenery in nests built to attract secondary females later in the season (Gwinner, 1997). Most interestingly, despite this year to year variation in both yolk testosterone and amounts of nest greenery there was a strong positive correlation of greenery and yolk testosterone.

Several effects of green nest material have been demonstrated. First, females are attracted by green plants in nests and displayed by males (Fauth et al., 1991; Brouwer and Komdeur, 2004; Veiga, 2006; Gwinner, 2013). Second, volatile secondary plant compounds enhance nestling immune function in starlings and Blue tits (Gwinner et al., 2000; Mennerat et al., 2009 a, b ); third, volatile plant compounds control nest ectoparasites and pathogens (Clark and Mason, 1985; Gwinner and Berger, 2005; Shutler and Campbell , 2007; Mennerat et al., 2009a, b; reviewed by Dubiec, et al., 2013). Yolk testosterone, on the other hand, enhances nestling growth in European starlings (Swedish starling population: Pilz et al., 2004; our starling population: E. Yohannes et al., unpubl.) as in several other species e.g., canaries Serinus sp. (Schwabl, 1996) Blue tits Cyanistes caeruleus (Tschirren et al., 2005), and Grey partridges Perdix perdix (Cucco et al., 2008). Our results suggest that females respond to the amount of nest herbs with adjustments of yolk testosterone concentrations. Green herbs used by starlings have immune-enhancing and bactericidal potential (Roitt et al., 1996; Wagner and Wiesenauer, 2003) and might offset negative effects of yolk testosterone (or testosterone induced fast growth) on immune function (Groothuis et al., 2005; Müller et al., 2007). Consistent with this hypothesis, female Great tits reduced yolk testosterone concentrations in nests with high ectoparasite loads (Tschirren et al., 2004), although yolk testosterone-enhanced growth was not accompanied by a blunted immune function in this species (Tschirren et al., 2005).

According to the differential allocation hypothesis (Gil et al., 1999) females, when paired with an attractive male (signaling high quality), increase amounts of growth promoting hormones, such as testosterone, in their eggs. Yolk testosterone concentrations have been shown to be related to variation of plumage or leg colour, tail length, and song quality (Gil et al., 2004; Loyau et al., 2007; Kingma et al., 2009; Garcia-Fernandez et al., 2010; Alonso-Alvarez et al., 2012). Our study suggests that, male presentation of green plants to the female, an integral component of male starling courtship display behaviour, and/or the presence of green plants in the nest, induce an increase of yolk testosterone concentrations. Since testosterone induces males to incorporate more green plants into their nest (De Ridder et al., 2000), it is possible that females ultimately select males with high androgen levels.

In contrast to our study, experimentally added greenery to nests increased clutch size but had no effect on yolk testosterone in the congeneric Spotless starling (LopezRull and Gil, 2009). This difference from our results may suggest that a male's ritualised courtship behaviour which includes the display of green plants to the female, singing, fluffing and the showing of iridescent breast feathers, and wing flapping is more important for the yolk testosterone response than the presence of green plants in the nest alone. The suite of courtship behaviours may provide cues for a female's reproductive investment but particularly the presentation of green nest material may signal direct benefits for the female and her offspring.

\section{ACKNOWLEDGEMENTS}

We are very grateful to all the people, who were involved in this study. L. Trost, M. Oltrogge, W. Jensen and E. Koch assisted in the field. M. Valcu and W. Forstmaier helped with statistics. The late Ebo Gwinner provided numerous good advice and discussions and the opportunity to perform this study. B. Kempenaers gave support in various ways.

\section{REFERENCES}

Alonso-Alvarez, C., Perez-Rodriguez, L., Ferrero, M.E., de-Blas, E.G., Casa, F. and Mougeot, F. (2012) Adjustment of female reproductive investment according to male carotenoidbased ornamentation in a gallinaceous bird. Behav. Ecol. Sociobiol., 66, 731-742.

Alvarez, E., Belada, E., Verdejo, J. and Barba, E. (2013) Variation in Great tit nest mass and compostion and its breeding consequences: a comparative study in four Mediterranean habitats. Avian Biol. Res., 6, 39-46.

Brouwer, L. and Komdeur, J. (2004) Green nest material has a function in mate attraction in European starling. Anim. Behav., 67, 539-548.

Clark, L. and Mason, J.R. (1985) Use of nest material as 
insecticidal and anti-pathogenetic agents by the European starling. Oecologia, 67, 169-176.

Clark, L. and Mason, J.R. (1988) Effect of biologically active plants used as nest material and derived benefits to starling nestlings. Oecologia, 77, 174-180.

Clark, L. (1991) The nest protection hypothesis: the adaptive use of plant secondary plant compounds by European starlings. In: Loye, J.E and Zuk, M. (eds), Bird parasite interactions: ecology, evolution, and behaviour, pp. 205-221. Oxford University Press.

Coslovsky, M., Groothuis, T., de Vries, B. and Richner, H. (2012) Maternal steroids in egg yolk as a pathway to translate predation to off spring: experiments with great tits. Gen. Comp. Endocr., 176, 211-214.

Cucco, M., Guasco, B., Malacarne, G., Ottonelli, R. and Tanvez, A. (2008) Testosterone levels and dietary carotenoids influence growth and immunity of grey partridge chicks. Gen.Comp. Endocr. 156, 48-425.

Cunningham E. and Russell, A.F. (2000) Egg investment is influenced by male attractiveness in the mallard. Nature 404, 74-77.

De Ridder, E., Pinxten, R., Mees, V. and Eens, M. (2000) Short- and long-term effects of male-like concentrations of testosterone on female European starlings (Sturnus vulgaris). Auk, 119, 487-497.

Deeming, D.C. (2002) Avian incubation. behaviour, environment, and evolution. Oxford University Press.

Dubiec, A., Góźdź I., and Mazgajski,T.D. (2013) Green plant material in avian nests. Avian Biol. Res., 6, 133-146.

Eens, M. and Pinxten, R. (1993) Function of the song and song repertoire in the European starling (Sturnus vulgaris): An aviary experiment. Behaviour, 125, 51-66.

Eising, C M., Eikenaar, C., Schwabl, H. and Groothuis, T, (2001) Maternal androgens in black-headed gull (Larus ridibundus) eggs: Consequences for chick development. Proc. R. Soc. B: Biol. Sci., 268, 839-846.

Feare, C. (1984) The Starling. Oxford University Press.

Fauth, P., Krementz, D. and Hines, J. (1991) Ectoparasitism and the role of green nesting material in the European starling. Oecologia, 88, 22-29.

Garcia-Fernandez, V., Guasco, B., Tanvez, A., Lacroix, A., Cucco, M., Leboucher, G. and Malacarne, G. (2010) Influence of mating preferences on yolk testosterone in the grey partridge . Anim. Behav., 80, 45-49.

Gil, D., Graves, J., Hazon, N. and Wells, A. (1999) Male attractiveness and differential investment in zebrafinch eggs. Science, 286, 126-128.

Gil, D., Leboucher, G., Lacroix, A., Cue, R. and Kreutzer, M. (2004) Female canaries produce eggs with greater amount of testosterone when exposed to preferred male song. Horm. Behav., 45, 64-70.

Gil, D., Marzal, A., de Lope, F., Puerta, M. and Møller, A.P. (2006) Female house martins (Delichon urbica) reduce egg androgen deposition in response to a challenge of their immune system. Behav. Ecol. Sociobiol., 60, 96-100.

Groothuis, T.G.G., Müller,W., von Engelhardt, N., Carere, C. and Eising, CM. (2005) Maternal hormones as a tool to adjust offspring phenotype in avian species. Neurosci. Biobehav. Rev., 29, 329-352.

Gwinner, H. (1997) The function of green plants in nests of European starlings (Sturnus vulgaris) Behavior, 134, 337351.

Gwinner, H., Oltrogge, M., Trost, L. and Nienaber, U. (2000) Green plants in starling nests: effects on nestlings. Anim. Behav., 59, 301-309.

Gwinner, H. and Berger, S. (2005) European starlings: nestling condition, parasites and green material during breeding season. J. Ornithol., 146, 365-371.

Gwinner, H. (2013) Male European starlings use odorous herbs as nest material to attract females and benefit nestlings. Chemical signals in vertebrates, Vol. XII. Springer, New York.

Hansell, M. and Overhill, R. (2000) Bird nests and construction behaviour, pp 189. Cambridge University Press.

Heylen, D., Müller W., Groothuis, T.G.G. and Matthysen, E. (2012) Female great tits do not alter their yolk androgen deposition when infested with a low-transmittable ectoparasite. Behav. Ecol. Sociobiol., 66, 287-293.

Kessel, B. (1957) A study of the breeding biology of the European starling (Sturnus vulgaris L.) in North America. Am, Mid. Nat., 58, 257-331.

Kingma, S.A., Komdeur, J., Vedder, O., von Engelhardt, N., Korsten, P. and Groothuis, T.G.G. (2009) Manipulation of male attractiveness induces rapid changes in avian maternal yolk androgen deposition. Behav Ecol., 20, 172-179.

Lampert, K. (1997) Eintrag von grünem Nestmaterial beim Star (Sturnus vulgaris). Diploma thesis University Würzburg.

Lopez-Rull, I. and Gil, D. (2009) Do females spotless starlings Sturnus unicolour adjust maternal investment according for male attractiveness? J. Avian. Biol., 40, 254-262.

Loyau, A., Saint Jalme, M., Mauget, R. and Sorci, G. (2007) Male sexual attractiveness affects the investment of maternal resources into the eggs in peafowl (Pavo cristatus). Behavl. Ecol. Sociobiol., 61, 1043-1052.

Marshall, R.C., Leisler, B., Catchpole, C.K. and Schwabl, H. (2005) Male song quality affects circulating but not yolk steroid concentrations in female canaries (Serinus canaria). J. Exp. Biol., 208, 4593-4598.

Mennerat, A., Mirleau, P., Blondel, J., Perret, P., Lambrechts, M. and Heeb, P. (2009a) Aromatic plants in nests of blue tits Cyanistes caeruleus protect chicks from bacteria. Oecologia, 161, 849-855.

Mennerat, A., Perret, P. and Bourgault, P. (2009b) Aromatic plants in nests of blue tits: positive effects on nestlings. Anim. Behav., 77, 569-574.

Moreno, I., Soler, M.,Moller,A.P. and Linden M. (1994) The function of stone carrying in the black wheatear Oenanthe leucurua. Anim.Beh., 47, 1297-1309

Moreno, A.(2013)Avian nests and nest-building as signals.Avian Biol. Res., 6, 133-146.

Müller, W., Groothuis, T.G.G., Kasprzik, A., Dijkstra, C., Alatalo, R.V. and Siitari, H. (2007) Prenatal androgen exposure modulates cellular and humoral immune function of blackheaded gull chicks. Proc. R. Soc. B., 272, 1971-1977. 
Navarra, K., Hill, G. and Mendonca, M. (2006) Yolk testosterone stimulates growth and immunity in house finch chicks. Physiol. Biochem. Zool., 79, 550-555.

Pilz, K M, Quiroga, M., Schwabl, H. and Adkins- Regan E. (2004) European starling chicks benefit from high yolk testosterone during a drought year. Hormon. Behav., 46, 179-192.

Pinxten, R. and Eens, M. (1990) Polygyny in European starling: effect on female reproductive success. Anim. Behav., 40, 1035-1047.

Roitt, IM., Brostoff, J. and Male, D. (1996) Immunology, 4th edn. Mosby, London.

Saino, N., Ferrari, R.P., Romano, M., Martinelli, R., Lacroix, A., Gil, D. and Møller, A.P. (2006) Maternal allocation of androgens and antagonistic effects of yolk androgens on sons and daughters. Behav. Ecol., 17, 172-181.

Schwabl, H. (1993) Yolk is a source of maternal testosterone for developing birds. Proc. Nat. Acad. Sci. USA, 90, 1144611450.

Schwabl, H. (1996) Maternal testosterone in the avian egg enhances post-natal growth. Comp. Biochem. Physil., 114 A, 271-276.

Shutler, D. and Campbell, A.A. (2007) Experimental addition of greenery reduces flea loads in nests of a non-greenery using species, the tree swallow Tachycineta bicolour. J. Avian Biol., 38, 7-12.

Tanvez, A., Beguin, N., Chastel, O., Lacroix, A. and Leboucher, G. (2004) Sexually attractive phrases increase yolk androgens deposition in Canaries (Serinus canaries) Gen. Com. Endoc., 138, 113-120.

Tschirren, B., Richner, H. and Schwabl, H. (2004) Ectoparasitemodulated deposition of maternal androgens in great tit eggs. Proc. R. Soc. B., 271, 1371-1375.

Tschirren, B., Saladin, V., Fitz, P., Schwabl, H. and Richner, H. (2005) Maternal yolk testosterone does not modulate parasite susceptibility or immune function in great tit nestlings. J. Anim. ECo., 74, 675-682.

Veiga, J., Polo,V. and Vinuela, J. (2006) Nest green plants as a male status signal and courtship display in the spotless starling. Ethology, 112, 96-204.

Vergauwen, J., Goerlich, V.C., Groothuis, T.G., Eens, M. and Müller, W. (2012) Food conditions affect yolk testosterone deposition but not incubation attendance. Gen. Com. Endocr., 153, 112-119.

Wagner, H. and Wiesenauer, M. (2003) Immunomodulatory agents from plants. Birkhäuser Verlag, Basel. 